Editorial of the Special Issue:

\title{
Trade and Logistics in an Era of Asian Integration
}

\author{
Tsung-Chen Lee*, Kai-Chieh Hu**, Paul Tae-Woo Lee***
}

In past decades, the Asian countries have made strenuous efforts in engaging free trade agreements (FTAs). This fact leads to a new era of commodity trade in the continent, and as a consequence, a restructure in the value chain of production network and a change in consumers' preferences. As a key role in commodity transport, the industries of ports, shipping, aviation, and logistics facilitate the realization of economic gains from trade liberalization. A larger volume of shipping demand and a structural change in trade flows bring a new competition environment to the industries. Their efficiency, operation strategies, service quality are topics of heated discussion. In view of the fact that Asia is the most prosperous region in terms of economic cooperation, the Asian experiences in trade liberalization and the development of maritime logistics are relevant to Asia itself and other continents. This Special Issue collects three papers which were submitted to 2015 SUBA and Asian Logistics Round Table (ALRT) Conference held on 31 August - 1 September 2015 at Soochow University in Taiwan. The main theme of the conference was "Global Integration of Economies and Connectivity Development." In the growing globalized economy in tandem with FTAs and regional economic blocks development both maritime connectivity is a critical element to promote regional economic development, affecting structural change in trade flows, and relocation of production lines, multimodal transport systems. Having considered the above, we have selected three choice papers which are related to trade (exports and imports) and maritime logistics in the Asian countries.

The first paper in this issue by Shih-Mo Lin and Hong Linh Dinh explores the value chain transition in the East Asian production network during the period of 1995-2011. The authors adopt decomposition method and multi-national input-output tables from World

\footnotetext{
* Department of Economics, National Taipei University, Taiwan

** Department of Business Administration, Soochow University, Taiwan

*** Institute for Supply Chain and Logistics, College of Business, Victoria University, Australia
} 
Input-Output Database (WIOD) for the empirical analysis on six countries, consisting of Taiwan, China, Japan, Korea, Indonesia, and India. Based on their results, the share of domestic value-added (DVA) has been unchanged or declined in the six countries, implying that there is a trend of increasing foreign contents in export production. As for the individual countries, Taiwan's DVA absorbed in China has increased over time, and a large part of Taiwan's DVA absorbed in China has been through intermediate products and intermediates that are then re-exported to a third countries. In addition, there is also an increasing trend of South Korea's DVA absorbed by China's final demand, as well as its domestic and export production. Finally, China's export production has used more value-added sourced from Taiwan and South Korea starting from the year of 1995.

The paper by Tzu-Han Yang and Han-Pang Su aims at analyzing how preference change affects the import demand, and consequently alters the estimations of trade liberalization policy on its macroeconomic performance. Taking Taiwan as a case study, the authors highlight the significance of preference changes in simulating the scenarios of trade liberalization. Neglecting the preference change would yield biased prediction. Specifically, their results suggest that the effects of Taiwan's import preferences partly offset the positive economic effects of the tariff reduction policy. The impacts of trade liberalization in terms of economic growth would be overestimated in the case of neglecting preference change.

The paper by Mohamad Reza, Kamonchanok Suthiwartnarueput, and Pongsa Pornchaiwiseskul explores the main research question regarding which indicator in the existing liner shipping connectivity index (LSCI) can provide the most significant impacts towards the improvement of its economic growth and trade volume in six maritime South-East ASEAN countries, consisting of Indonesia, Malaysia, Philippines, Singapore, Thailand, and Vietnam. As suggested by the empirical results, among the LSCI indicators, "port's capacity to accept larger ship size" is the most significant one. In addition, for Malaysia and Singapore which have a world class liner shipping infrastructure, improving the number of liner shipping services is the strategy to keep its reputation and ranking. For the rest of the four countries, however, the priority is to enhance the supporting liner shipping infrastructure. The LSCI needs to cover newly proposed concepts of economies of low, connection and fusion technology (Lee and Lee, 2015) to enrich characteristics and aims of the index.

Although the studies on Asian economic integration have increased in recent years, the linkage between trade liberalization and maritime logistics needs much further attention. In addition, we need to pay attention to Chinese government initiative of the "Silk Road Economic Belt and the 21st-Century Maritime Silk Road" (the One Belt and One Road: 
OBOR) in tandem with her growing engagement in China-Africa-South America trade (Lee, 2015). With launching the Asia Infrastructure Investment Bank (AIIB) in 2015, in which 57 countries have joined as members, the OBOR is expected to contribute promoting the connectivity of Asian, European and African continents and their adjacent seas and developing connectivity networks. Having said that, a firmer analytical and integrated framework on the linkage will pave the way for a more comprehensive understanding of the dynamics of Asian integration, and the role of maritime logistics in facilitating international trade. We look forward to more works in the future in the Journal of International Logistics and Trade as a discussion forum. 


\section{References}

Lee, P.T.W. (2015), China's Growing Engagement in Emerging Maritime Logistics Market in Africa, In Lee, P.T.W. and Cullinane, K. (eds.) (2015), Dynamic Shipping and Port Developments in the Globalized Economy. Vol. 1: Applying Theory to Practice in Maritime Logistics. England: Palgrave MacMillan.

Lee, P.T.W. and Lee, T-C (2015), New Concepts of Economies of Flow, Connection, and Fusion in Maritime Logistics. In Lee, P.T.W. and Cullinane, K. (eds.) (2015), Dynamic Shipping and Port Developments in the Globalized Economy. Vol. 1: Applying Theory to Practice in Maritime Logistics. England: Palgrave MacMillan. 